\title{
Clinical epidemiological study of uterine prolapse
}

\author{
Parvathavarthini K. ${ }^{1}$, Vanusha A. $^{2 *}$
}

\begin{abstract}
${ }^{1}$ Department of Obstetrics and Gynecology, Karpaga Vinayaga Institute of Medical Sciences and Research Centre, Chennai, Tamil Nadu, India

${ }^{2}$ Department of Obstetrics and Gynecology, Saveetha Medical College and Hospital, Chennai, Tamil Nadu, India
\end{abstract}

Received: 06 December 2018

Accepted: 18 December 2018

\section{*Correspondence:}

Dr. Vanusha A.,

E-mail: vanusaarumuga@gmail.com

Copyright: ( $)$ the author(s), publisher and licensee Medip Academy. This is an open-access article distributed under the terms of the Creative Commons Attribution Non-Commercial License, which permits unrestricted non-commercial use, distribution, and reproduction in any medium, provided the original work is properly cited.

\begin{abstract}
Background: Pelvic organ prolapse is one of the common gynaecological problem in India among the parous and aged women. Though the pelvic organ prolapse is not life threatening if left untreated it can lead to many social issues and also it reduces the quality of life of a woman. Thus, this study aims at generating epidemiological data on uterine prolapse in a clinical setting and identifying its risk factors so that appropriate measures can be taken to prevent the same.

Methods: It was a descriptive case control study. Using a study proforma the required information was collected from the patients admitted with uterine prolapse (case) and from amongst the patient's attendees of Gynaecology ward (control). Obtained data were compared and analyzed using appropriate statistical methods.

Results: Uterine prolapse contributes to about $5.9 \%$ of the total gynecological patients admitted during the study period. The mean age of presentation with uterine prolapse was 50.1years the mean number of deliveries was higher in case compared to the control with the mean of 4 deliveries. Out of 130 patients, only $13.9 \%$ of them had institutional delivery while the others had home delivery.

Conclusions: Uterine prolapse is strongly associated with age, parity and place of delivery. As the risk factors for uterine prolapse are easily preventable public health awareness programme must be conducted on its risk factors there by reducing the incidence of prolapse and decreasing the morbidity caused by it.
\end{abstract}

Keywords: Epidemiological, Parity, Risk factors, Uterine prolapse

\section{INTRODUCTION}

Uterine prolapse is descent of uterus from its anatomical confines to positions within or outside the vaginal introitus. Uterine prolapse occurs when pelvic floor muscles and ligaments stretch and weaken, providing inadequate support for the uterus. Though the predisposing factors for weakening of muscles and ligaments are multifactorial they can be easily preventable. $^{1}$ Causes of utering prolapse are multifactorial of which mode of delivery plays an important role..$^{2-5}$ Uterine prolapse is a significant public health problem in most of the developing countries as it affects the physical and mental health of women. ${ }^{6}$ This is a common condition and generally thought to aggravate over time. Even in developed countries such as UK, one per 1000 women were admitted to hospital with a diagnosis of utero-vaginal prolapse and around $20 \%$ of women with this gynaecological problem are on waiting lists for major surgery. ${ }^{7}$ It has been estimated that over the next 30 years, the demand for treatment of prolapse will increase $45 \%$, commensurate with an increase in the population of women older than 50 years of age.

In India studies on clinical epidemiology of uterine prolapse are limited. Further information available on the risk factors is based on studies carried out elsewhere and may not be valid for Indian situation. The determinants of 
this health condition may be different depending upon the life style of the people, socio-cultural features and health care seeking behaviour of the people.

Therefore, information on the clinical epidemiology and risk factors of uterine prolapse are highly warranted so as to suggest measures to prevent prolapse among the risk groups in Indian situation. Further, the association between different risk factors must be better understood for counselling and managing women appropriately. Thus, this study aims at generating the epidemiological data on uterine prolapse in a clinical setting and identifying its risk factors.

\section{METHODS}

This study was a hospital based descriptive Case-control study conducted in Rajiv Gandhi Government Hospital for women and Child, Pondicherry for a period of 18 months. This study was conducted after getting approval from the Institutional Human Ethics Committee. Patients who were admitted in Gynaecology ward with uterine prolapse of any degree during the study period were used as the source population (referred as cases).

Equal numbers of normal women were identified from amongst patient's attendees of gynaecology ward and were included as control. Occurrence of uterine prolapse among gynaecological patients admitted in hospital was assessed. A total of 130 cases of uterine prolapse were admitted in the hospital for treatment during present study period.

A well-designed study proforma was developed and used to obtain information from both case and control groups. The proforma consisted of patient/normal women profile, socio-economic parameters, risk factors, symptoms and examination findings.

The data collected were computed, cleaned and analysed using Microsoft Excel spreadsheet. The data were transformed and statistically analysed using computer software SPSS version 16.0.

The various parameters thus collected were classified as obstetric and non-obstetric risks and compared between cases and controls.

The results were also compared with similar other studies.

\section{RESULTS}

A total of 2184 cases were admitted in the Gynaecology ward in the Department of Obstetrics and Gynaecology, Rajiv Gandhi Government Women and Children, a tertiary hospital in Puducherry during the study period. The number of cases diagnosed with uterine prolapse was 130, constituting $5.9 \%$ of the total patients admitted during the study period (Figure 1).

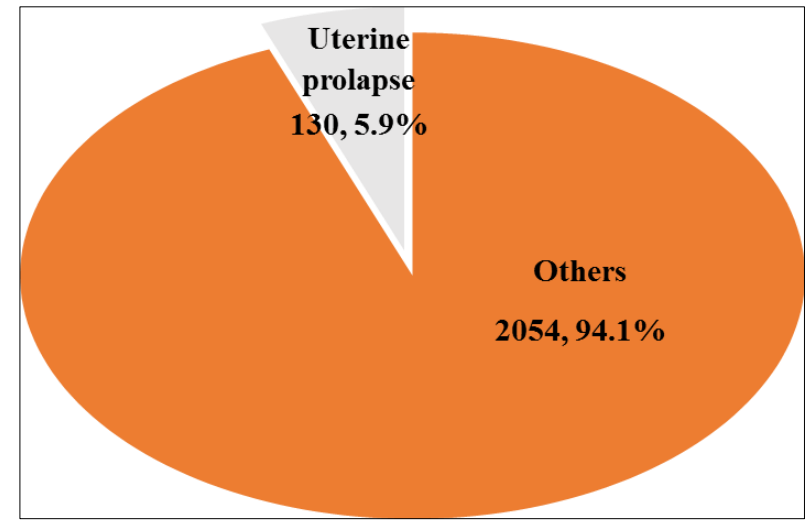

Figure 1: Total number of admissions in gynaecology ward in RGGWCH during the study period $(n=2184)$.

Majority of the patients are from rural area. The distribution of cases and controls in relation to socioeconomic status is shown in Table 1.

Table 1: Distribution of cases in relation to socioeconomic status.

\begin{tabular}{|l|l|l|l|l|}
\hline & $\begin{array}{l}\text { Lower } \\
\text { class }\end{array}$ & $\begin{array}{l}\text { Lower middle } \\
\text { class }\end{array}$ & $\begin{array}{l}\text { Middle } \\
\text { class }\end{array}$ & $\begin{array}{l}\text { Upper } \\
\text { class }\end{array}$ \\
\hline Case & 125 & 0 & 5 & 0 \\
\hline Control & 121 & 1 & 6 & 2 \\
\hline
\end{tabular}

Majority of them belong to lower class in both cases and controls, the proportion is relatively higher in cases but not statistically significant $(\mathrm{t}=1.2 ; \mathrm{p}=0.27)$ with an odds ratio of 1.8 .

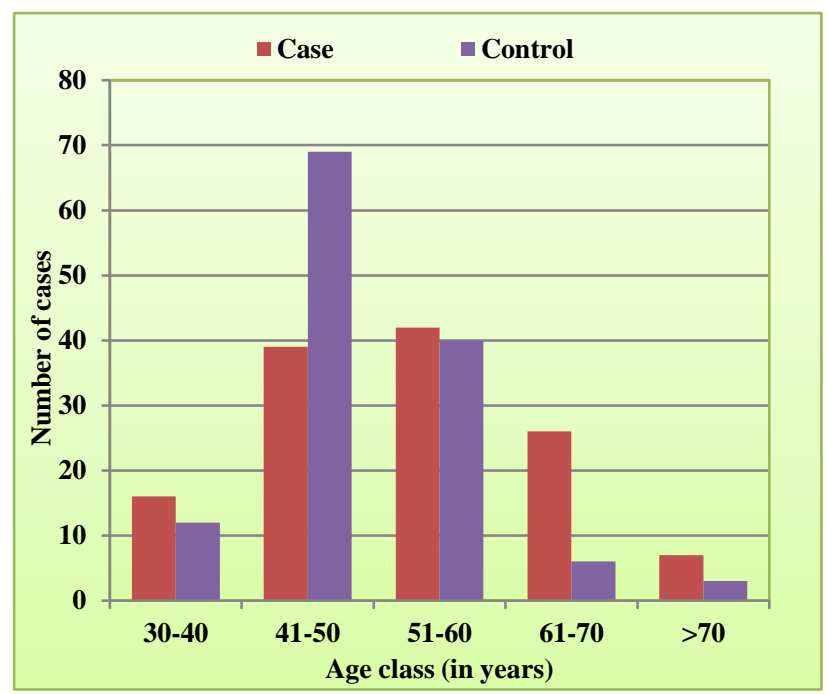

Figure 2: Distribution of study subjects in relation to age class.

About $56.5 \%$ of the subjects (cases: $51.5 \%$; control: $61.5 \%$ ) were housewives, followed by labourers (cases: 31.9\%; control: $28.5 \%$ ) and others (case:13.1\%; control: $10.1 \%)$. There was no difference in the occupation of the cases and controls ( $>>0.05)$. The age of the cases ranged 
from 30 and 80 years with a mean of 54.4 (95\% CI: $52.5-$ 56.3). The mean age of the controls was 50.1 years $(95 \%$ CI: 48.7-51.4), with the range of 40-80 years.

The mean age was significantly higher among the case when compared to controls $(\mathrm{t}=3.61 ; \mathrm{p}<0.05)$. Distribution of cases and control in relation to age classes showed that the number of cases showed an increase from 30-40 years of age, reaching its peak in 40-60 and showed a decline thereafter (Figure 2) (Figure 3). Majority of the controls belong to 30-40 years. The mean age at onset of symptoms of uterine prolapse among the cases was 50.8 years (95\% CI: 49.1-52.6). The complaints associated with uterine prolapse are shown in table 2. The occurrence of each complaint mean and range of duration of each complaint along with $95 \%$ confidence intervals are also given in the table.

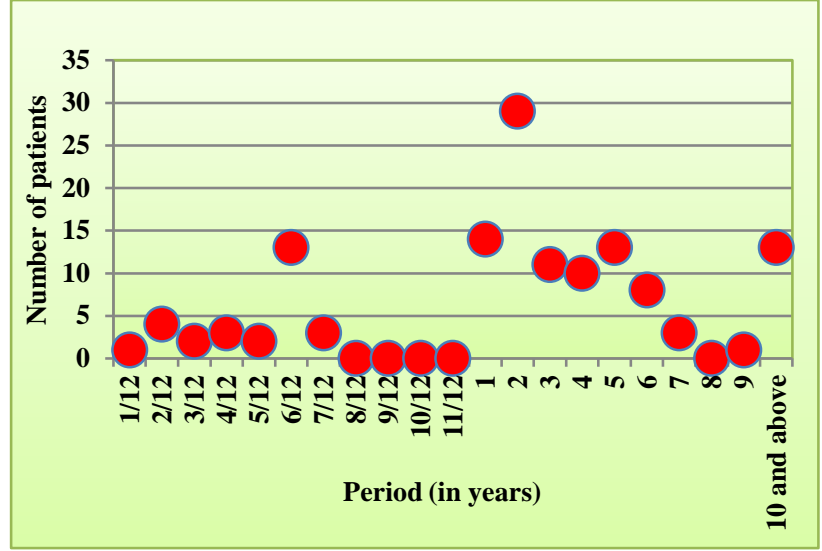

Figure 3: Distribution of cases in relation to duration of mass descending per vagina.

Table 2: Chief complaints among the cases with uterine prolapse.

\begin{tabular}{|c|c|c|c|c|c|c|}
\hline \multirow{3}{*}{ Complaint } & \multicolumn{3}{|c|}{ Cases reported } & \multicolumn{3}{|l|}{ Duration } \\
\hline & & \multirow{2}{*}{$\%$ out of 130} & \multirow{2}{*}{ Range } & \multirow{2}{*}{ Mean } & \multicolumn{2}{|c|}{ 95\% CI (in years) } \\
\hline & & & & & Lower & Upper \\
\hline Mass descending per vagina & 130 & 100 & 30 days- 30 years & 3.5 years & 2.71 & 3.75 \\
\hline Bulge at perineum & 0 & 0.0 & - & - & - & \\
\hline Pain at vulva & 12 & 9.2 & 30 days-1 year & 13 days & 0.22 & 0.54 \\
\hline Vaginal discharge & 43 & 33.1 & 07 days- 3 years & 23 days & 0.05 & 0.33 \\
\hline Urinary problems & 60 & 46.2 & 07 days- 2 years & 48 days & 0.16 & 0.38 \\
\hline Defecation problem & 14 & 10.8 & 7 days-4 months & 62 days & 0.09 & 0.27 \\
\hline Coital problem & 0 & 0.0 & - & - & - & \\
\hline Chronic low back ache & 26 & 20.0 & 30 days- 2 years & 67 days & 0.66 & 1.19 \\
\hline Abnormal bleeding & 1 & 0.8 & - & 90 days & - & \\
\hline Other symptoms & 0 & 0.0 & & & & \\
\hline
\end{tabular}

The distribution of cases in relation to duration of mass descending at the time of admission showed that maximum number of cases was in the range of 1-2 years (Figure 3). Analysis of duration of different complaints showed significantly higher duration of mass descending per vagina. The shortest duration was pain in vulva followed by vaginal discharge, urinary problem and defecation problems. The duration of these complaints did not vary significantly (Table 2). These symptoms appear to be the compelling complaints to seek early care. However, chronic low back ache was significantly higher than these symptoms. Further analysis of complaints showed that occurrence of pain in vagina was related to the duration of mass descending per vagina. Other complaints such as vaginal discharge, urinary problem and chronic low back pain were irrespective of the duration of mass descending per vagina.

Analysis of uterine prolapse in relation to its degree (Figure 4) showed that no case with first degree of prolapse was reported. There were only three $(1.5 \%)$ cases with second. Majority of the cases $(114 ; 87.7 \%)$ were in the third degree. Procidentia (fourth degree prolapse) was observed in $13(10 \%)$ of the cases. Prolapse uterus showing ulceration was recorded in 14 $(10.7 \%)$ cases in the study group.

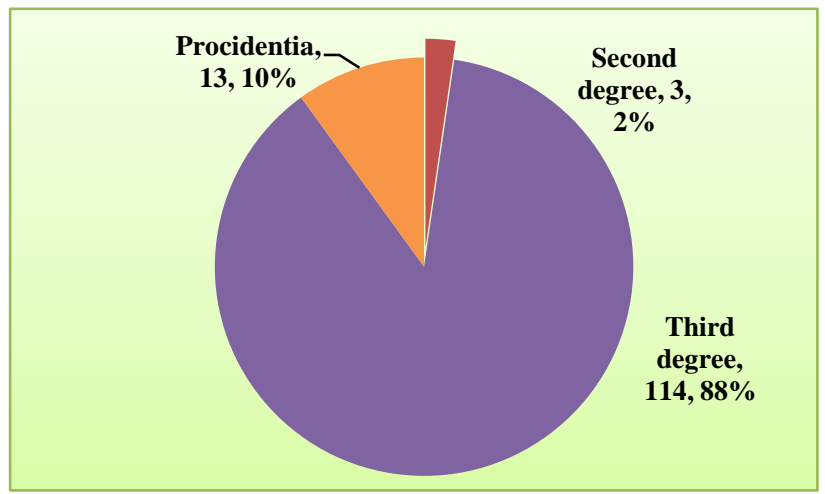

Figure 4: Uterine prolapse cases in relation to its degree $(n=130)$. 
Mean age of the cases with second degree prolapse was 51 years $(95 \% \mathrm{CI}=37.2-64.8)$, while it was 53.9 years (95\% CI= 51.9-55.8) for third degree (Figure 5).

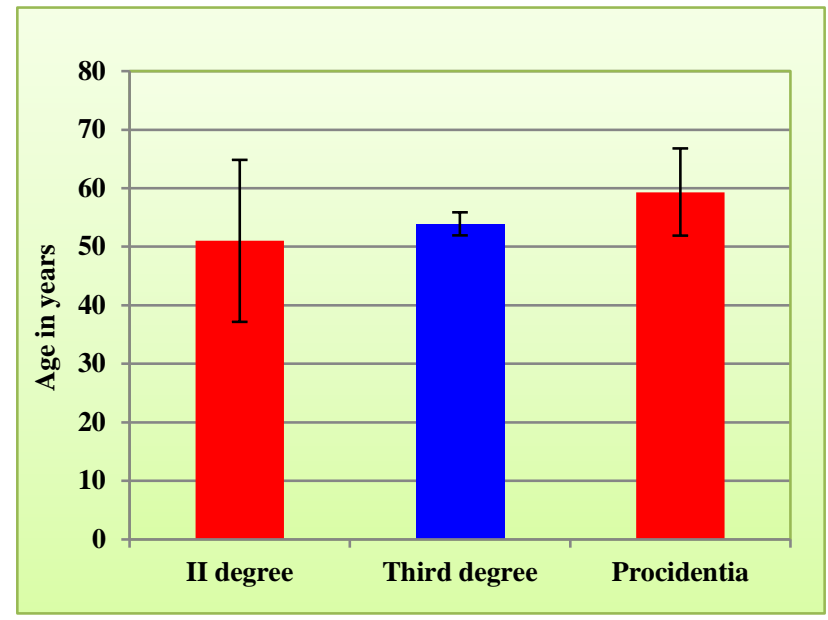

Figure 5: Mean age of the cases in relation to degree of POP $(95 \% \mathrm{CI})$.

Age of the procidentia was relatively higher with a mean of 59.3 years $(95 \% \mathrm{CI}=51.8-66.7)$, but the difference is at its statistical limit $(\mathrm{t}=1.62 ; \mathrm{p}=0.054)$. The increase in the degree of prolapse with age was also not significant $(\mathrm{r}=0.159 ; \mathrm{p}=0.07)$. The age at onset of symptoms in relation to degree of prolapse showed mean age of 47.8 , 50.7 and 52.6 years respectively for second, third and fourth degree. The increase in severity in terms of degree of prolapse was also not significantly correlated $(\mathrm{r}=0.073$, df: $128 ; p=0.406)$. Association of uterine prolapse with other types of pelvic organ prolapse such as cystocele, rectocele and enterocele were also examined (Figure 6) and compared its occurrence in relation to the degree of prolapse.

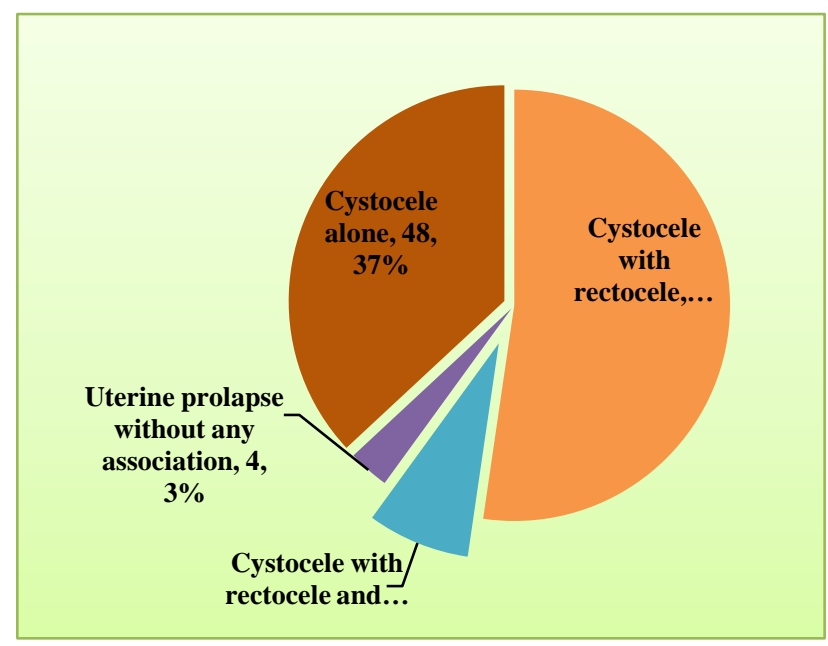

Figure 6: Conditions associated with POP $(n=130)$.

Three cases of uterine prolapse and one control were found to have suffered from Tuberculosis. COPD was observed only in one case. None of the cases and controls was suffering from anemia, undernourishment, constipation, hypermobility of joints, uterine polyp and respiratory and cardiovascular diseases.

The number of deliveries in the cases ranged from 1 to 8 with a total of 460 with an average of $4(95 \% \mathrm{CI}=3.28-$ $3.77)$. The total number of deliveries among the control group was 282 with an average of $3(95 \% \mathrm{CI}=2.56-$ 2.92) and range of 1-6. The mean number of deliveries was significantly $(\mathrm{t}=14.04 ; \mathrm{p}<0.05)$ higher in the uterine prolapse cases (Figure 7).

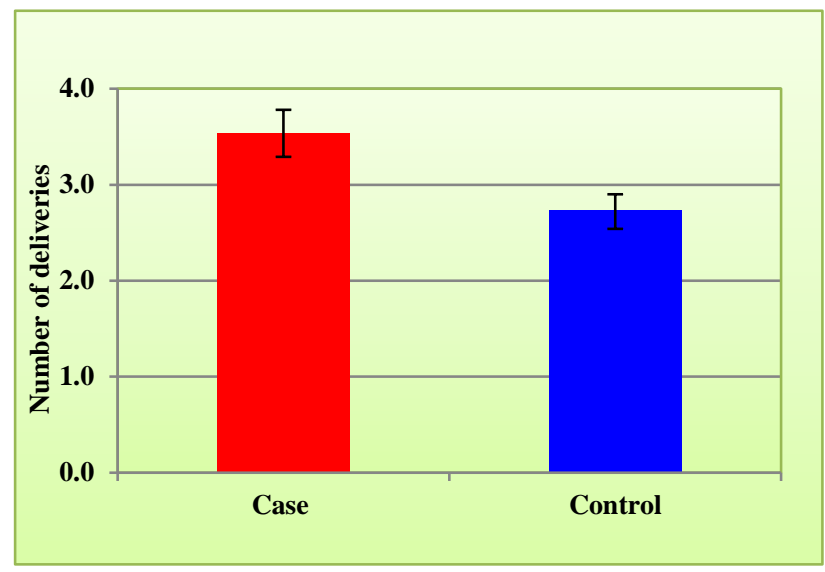

Figure 7: Mean deliveries of the cases and control (95\% CI).

Distribution of cases and controls in relation to number of deliveries showed relatively more number of cases in the higher number of deliveries (Figure 8).

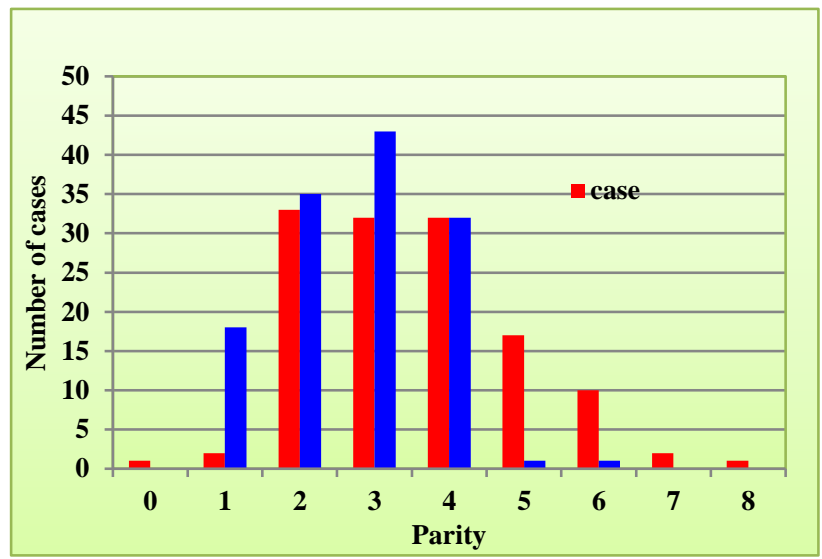

Figure 8: Distribution of cases and controls in relation to parity.

Examination of data on the place and type of delivery showed that in cases Institutional deliveries were only $13.9 \%$ and the rests were home deliveries. In the case of controls, majority $(74.4 \%)$ of the deliveries were Institutional and the difference was significant $\left(\chi^{2}=\right.$ 349.9; $\mathrm{p}=<0.05)$. All the institutional deliveries in the cases were vaginal, while 3 out of 282 deliveries in the control group were caesarians (Figure 9). 


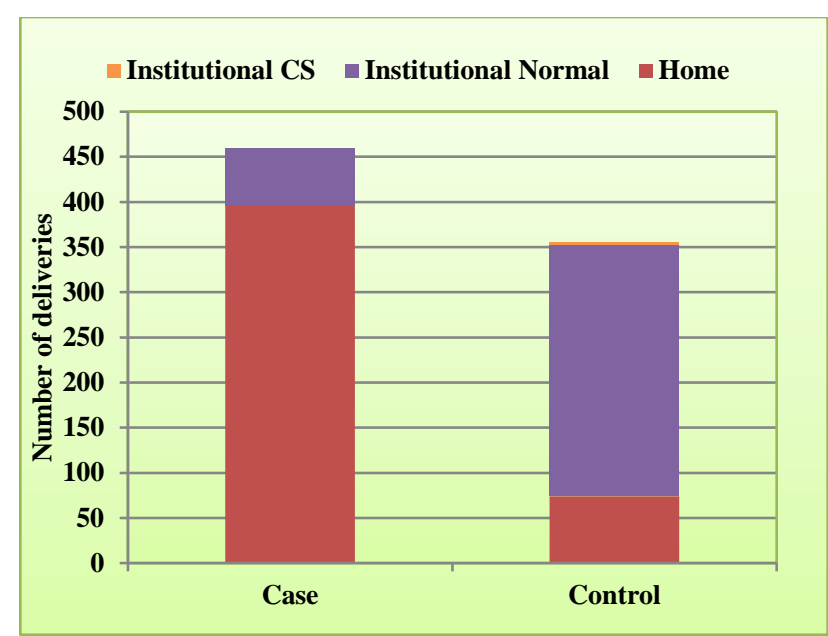

Figure 9: Mode of delivery among cases and controls.

Home deliveries are implied vaginal deliveries and are shown to be a major risk factor among the cases. The proportion of cases and controls attained menopause was 75.4 and $53.1 \%$ respectively (Figure 10 ).

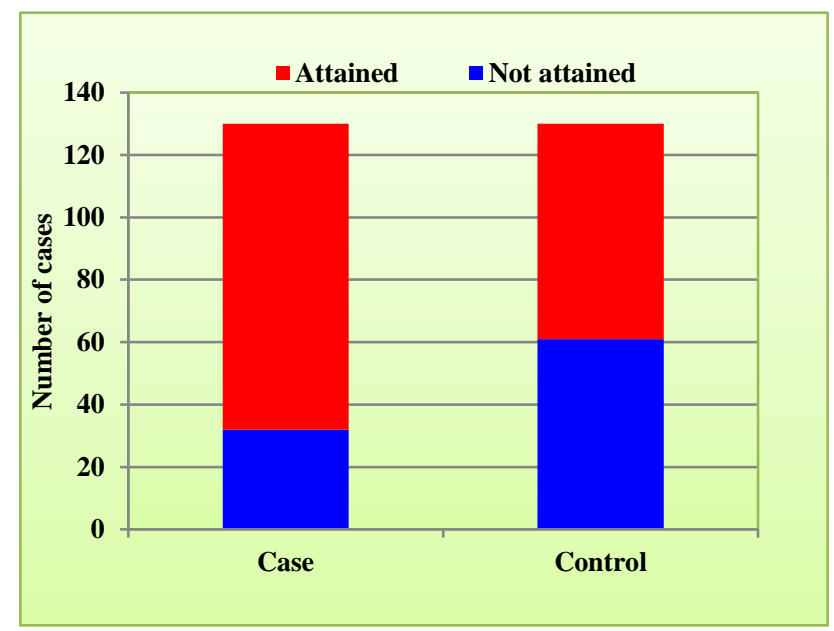

Figure 10: Distribution of cases in relation to attainment of menopause.

It was significantly higher in the cases $(\chi 2=14.02$; $\mathrm{p}=<0.05)$. Majority of the cases attained menopause before the age of 50 years (Figure 11) and there were cases who attained menopause after 50 years of age. The age of attainment of menopause among cases ranged from 40-56 years with a mean of 46.9 (95\% CI: 46.647.8). In the control group it ranged from $40-50$ years with a mean of 45.9 (95\% CI: 45.3-46.7). The difference was at its statistical limit $(\mathrm{t}=1.39 ; \mathrm{p}=0.07)$. Mean duration of menopause was analysed and it was 11.5 years in the cases (95\% CI: 9.9-13.0) and 9.2 years (95\% CI: $7.4-$ $10.9)$ and the difference is not significant $(\mathrm{t}=1.39$; $\mathrm{p}=0.17)$.

Univariate analysis showed significant association of age, parity and place of delivery with the outcome. These variables were used in multivariate analysis (logistic regression) and the results are shown in Table 3 and Figure 12.

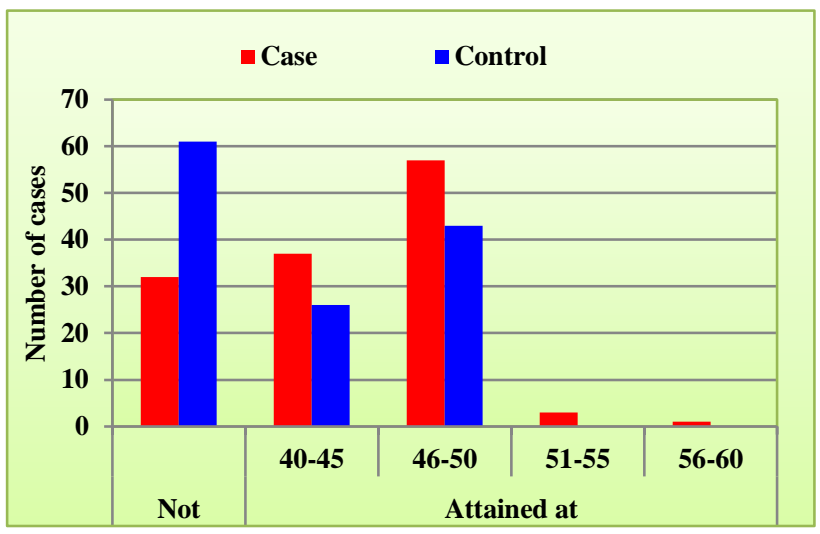

Figure 11: Distribution of cases and control in relation to the age of attainment of menopause.

Parity were grouped into three categories (1, 2, 3 and 4-8) and the age of the subjects were grouped into three categories ( $<45$ years, $46-55$ years and $>56$ years. The results showed that risks differ significantly between patients of different age- groups and parity $(\chi 2=47.7$, $\mathrm{P}<0.0001, \mathrm{df}=7$ ).

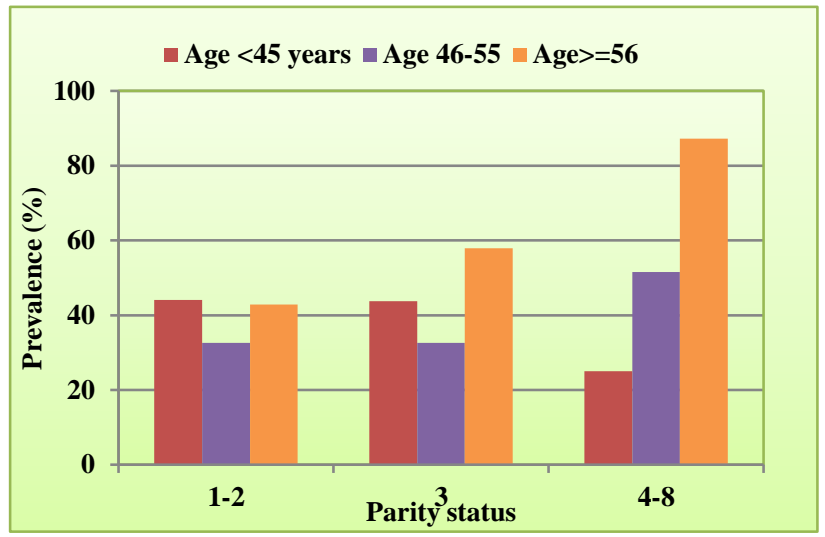

Figure 12: Association of outcome with age and parity.

Compared to parity 1 and 2, patients with parity 3 are 4 times at risk and parity more than 4 are 8 times at risk.

Table 3: Results of logistic regression of the parameters and outcome.

\begin{tabular}{|l|l|l|l|}
\hline Parameters & $\begin{array}{l}\text { Degrees of } \\
\text { freedom }\end{array}$ & $\begin{array}{l}\text { Wald } \\
\text { statistics }\end{array}$ & \begin{tabular}{l} 
P value \\
\hline Age
\end{tabular} \\
\hline Parity & 2 & 10.98 & $0.004^{*}$ \\
\hline Age and parity & 2 & 11.33 & $0.003^{*}$ \\
\hline Place of delivery & 2 & 11.57 & $0.019^{*}$ \\
\hline * significant & & 0.53 & 0.47 \\
\hline
\end{tabular}

Patients in age-group >60 years with parity 3 are 21.6 (95\% CI: 2.4-195.3) times at higher risk compared to all 
other combinations of age-groups and parity. The age and parity showed significant association but not the place of delivery. The interaction between age and parity also showed significant association with the outcome.

\section{DISCUSSION}

The present study showed that at least $6 \%$ of the patients who were admitted were suffering from uterine prolapse. Out of 130 uterine prolapse cases 124 cases had serious degree of prolapse warranting surgical intervention. This tertiary hospital receives patients not only from Pondicherry (population: 9 lakh) but also from neighboring districts of Tamil Nadu. This clinical epidemiological study was carried out, as populationbased surveys are difficult to undertake due to anticipated poor community compliance for intimate examination. The results of the study are comparable with that reported in a review of recent literature. ${ }^{8}$ Present analysis did not show any case of uterus prolapse in first degree. Majority $(88 \%)$ of the cases were in third degree of uterine prolapse. Procidentia was only $10 \%$. The results indicate that patients sought medical care for severe prolapse and mild cases were more likely to be ignored or the patients were reluctant.

A similar hospital-based study carried out in Ethiopia also showed only third and fourth degree prolapse cases among the uterovaginal prolapse cases against population-based surveys which showed prevalence of all the four degrees of uterine prolapse in Gambia and Ghana. ${ }^{9-12}$ Instance of self-cutting of a uterovaginal prolapse has been reported, showing the extend of sufferings faced by the patients with uterine prolapse. Studies have shown varying levels of prevalence of ulceration of prolapse uterus and in the present study it was $10.7 \%$ of the cases. ${ }^{9,13}$ Ulceration can be considered as severe complication resulting from lack of care.

All the uterine prolapse patients presented with complaint of mass descending per vagina. The other additional symptoms included pain in vagina, vaginal discharge, urinary and constipation problem and chronic low back pain. Though coital problem has been reported in other studies, it was not reported in the present study which may be due to bias in sharing personal problems. ${ }^{9}$ The mean duration of mass descending per vagina was 3.5 years while others were presented with short duration. This shows that these symptoms prompt the patients to seek care. Advancing age, parity and place of delivery were found to be the risks for developing uterine prolapse. The mean age of uterine prolapse among women in and around Pondicherry was 54 years which is higher than that reported from other studies, particularly in developing countries. ${ }^{14-16}$ Advancing age can be an indicator as other factors such as menopause (reduced level of estrogen hormone); change in body mass, comorbid conditions such as respiratory, cardio-vascular and diabetic diseases could contribute to the uterine prolapse. Menopause among the cases was relatively delayed when compared to the controls.

High parity is found to be a major risk factor as it was significantly higher than the controls. Also, the proportion of home deliveries (=vaginal deliveries) was significantly higher among cases. It is implied that repeated vaginal deliveries with prolonged labour tend to damage the muscles of the pelvic floor besides lifethreatening postpartum morbidities to a level of $10 \%$ as shown by a study in India. ${ }^{17}$ A similar observation was also reported from earlier studies in Africa. ${ }^{10} \mathrm{~A}$ number of studies have shown that high parity is a strong risk factor of uterine prolapse. ${ }^{18} \mathrm{~A}$ few studies have also shown that vaginal birth is not associated with pelvic organ prolapse and parity might not be the only risk factor and vice versa. ${ }^{19,20}$ A study carried out in Hyderabad concluded that pelvic organ prolapse was not necessarily the outcome of the repeated childbirth but often followed damage to the pelvic floor after the very first delivery. ${ }^{21}$ In the present study among the women in Pondicherry, variables such as body mass, presence of chronic obstructive pulmonary diseases and tuberculosis did not show any significant relation to uterine prolapse as shown by a similar case- control study elsewhere. ${ }^{22}$ Family history also did not show any relationship unlike such association observed in other studies. ${ }^{23,24}$ Similarly non-obstetric factors such as education, occupation and social status did not show any relationship with uterine prolapse. Though less education was reported to be a factor associated with uterine prolapse, the present analysis did not show any such association. ${ }^{25}$

\section{CONCLUSION}

Uterine prolapse is one of the gynaecological morbidities among women, strongly associated with age, parity and place of delivery. A number of risk factors with varying levels of association have been reported, but consistency was observed with only a few factors which can be easily preventable. Hence creation of awareness on the risk factors of uterine prolapse at community level should be a part of public health awareness programmes. Health advices during gynaecological consultations should be encouraged at both public and private sectors. During counseling information on the cause, symptoms and remedies of uterine prolapse should be covered. Educating pregnant women on pelvic floor exercises in the post-natal period helps in strengthening the pelvic floor muscles thereby preventing uterine prolapse. As the place of delivery has also been strongly associated with uterine prolapse measures to promote institutional delivery must be undertaken.

\section{ACKNOWLEDGMENTS}

Authors would like to thank Dr. K. Nanda Kumar, Medical Superintendent and Head of the Department of Orthopaedics and Dr. G. Arumugalakshmi, Specialist 
Grade I, Rajiv Gandhi Government Women and Children Hospital, Puducherry their support during study.

\section{Funding: No funding sources}

Conflict of interest: None declared

Ethical approval: The study was approved by the Institutional Ethics Committee

\section{REFERENCES}

1. Thapa B, Rana G, Gurung S. Contributing factors of utero-vaginal prolapse among women attending in Bharatpur hospital. J Chitwan Med Coll. 2014;4(9):38-42.

2. Gyhagen M, Bullarbo M, Nielsen TF, Milsom I. Prevalence and risk factors for pelvic organ prolapse 20 years after childbirth: A national cohort study in singleton primiparae after vaginal or caesarean delivery. BJOG. 2013;120(2):152-60.

3. Glazener C, Elders A, MacArthur C, et al. Childbirth and prolapse: Long-term associations with the symptoms and objective measurement of pelvic organ prolapse. BJOG. 2013;120(2):161-68.

4. Handa VL, Blomquist JL, McDermott KC, et al. Pelvic floor disorders after vaginal birth: Effect of episiotomy, perineal laceration, and operative birth. Obstet Gynecol. 2012;119(2 Pt 1):233-9.

5. Durnea CM, O'Reilly BA, Khashan AS, et al. Status of the pelvic floor in young primiparous women. Ultrasound Obstet Gynecol. 2015;46(3):356-62.

6. Smith FJ, Holman CDJ, Moorin RE, Tsokos N. Lifetime risk of undergoing surgery for pelvic organ prolapse. Obstet Gynecol. 2010;116(5):1096-100.

7. Doshani A, Roderick E C Teo, Christopher JM, Douglas G Tincello. Uterine prolapse. BMJ. 2007: 20;335(7624):819-23

8. South M, Amundsen CL. Pelvic organ prolapse: a review of the current literature. Minerva Ginecol, 2007;59(6):601-12.

9. Menur A, Hailemariam. Pelvic organ prolapse in Jimma University specialized hospital, Southwest Ethiopia. Ethiop J Health Sci., 2012;22(2):85-92.

10. Gumanga SK, Munkaila A, Malechi H. Social demographic characteristics of women with pelvic organ prolapse at the tamale teaching hospital, Ghana. Ghana Med J. 2014;48:208-13.

11. Scherf C, Morison L, Fiander A, Ekpo G, Walraven G. Epidemiology of pelvic organ prolapses in rural Gambia, West Africa. Bjog, 2002;109(4):431-6.

12. Osei K Wusu-Ansah, Henry S Opare-Addo. Pelvic organ prolapse in rural Ghana. Int J Obstetrics Gynecol 2008;103(2):121-4.
13. Rajalakshmi R, Bharathi S. A self-attempted cutting of a uterovaginal prolapse. J Obstet Gynaecol, 2007;27(2):207-8.

14. Dia A, Toure CT, Diop MB. Les prolapses genitaux a Dakar. Dakar Medi. 1991;36(1):39-46.

15. Lukman Y. Utero-vaginal prolapse: a rural disability of the young. East African Med J. 1995;72(1):2-9.

16. Moalli PA, Jones Ivy S, Meyn LA, Zyczynski HM. Risk factors associated with pelvic floor disorders in women undergoing surgical repair. Obstet Gynecol. 2003;101(5 Pt 1):869-74.

17. Iyengar K. Early postpartum maternal morbidity among rural women of Rajasthan, India: a community-based study. J Health Popul Nutr 2012;30(2):213-25.

18. Santhosh K. Indrajit W, Amarjeet S. Self-reported uterine prolapse in a resettlement colony of North India. J Midwife Women's Health, 2007;45(4):3418.

19. Eddie HM, Gerry H. Relation between vaginal birth and pelvic organ prolapse: J Acta Obstet et Gynecol. 2009;88(2):200-3.

20. Lukacz ES, DuHamel E, Menefee SA, Luber KM. Elevated postvoid residual in women with pelvic floor disorders: prevalence and associated risk factors. Int Urogynecol J Pelvic Floor Dysfunct. 2007;18(4):397-400.

21. Ramachandran AS. A statistical survey of prolapse of the uterus in relation to partiy and age. Journal of Obstetrics and Gynaecology of India, 1955;6:162-65.

22. Swift SE, Pound T, Dias JK. Case-control study of etiologic factors in the development of severe pelvic organ prolapse. Int Urogynecol $\mathbf{J}$ Pelvic Floor Dysfunct. 2001;12(3):187-92.

23. Rinne KM, Kirkinen PP. What predisposes young women to genital prolapse? Eur J Obstet Gynecol Reprod Biol. 1999;84(1):23-5.

24. Deval B, Rafii A, Poilpot S, Aflack N, Levardon M. Prolapse in the young woman: study of risk factors. Gynecol Obstet Fertil. 2002;30(9):673-6.

25. Nygaard I, Bradley C, Brandt D. Pelvic organ prolapse in older women: prevalence and risk factors. Obstet Gynecol. 2004;104(3):489- 97.

Cite this article as: Parvathavarthini K, Vanusha A. Clinical epidemiological study of uterine prolapse. Int J Reprod Contracept Obstet Gynecol 2019;8:7985. 